\title{
FEM Model for Studying Delamination in Fabric-reinforced Laminate Composites
}

\author{
Jacek Skrzypek ${ }^{1}$, Jacek Stadnicki ${ }^{2 *}$ \\ 'Avio Polska, 43-300 Bielsko-Biała, Grazyńskiego 141, Poland \\ ${ }^{2}$ University of Bielsko-Biała, Faculty of Mechanical Engineering and Computer Science, 43-309 Bielsko-Biała, Willowa 2, Poland
}

\section{BIOGRAPHICAL NOTES}

Jacek Stadnicki, Prof. Ph.D. D.Sc., works as a professor in the Department of Mechanical Engineering Fundamentals at University of Bielsko-Biała. His scientific and didactic work concerns the issues of machine designing and technology, computer aided engineering, optimization, Finite Element Method, dynamic of machines, textile machinery. He is the author or co-author of 89 original scientific journals in ISI master Journal List, 41 papers published in foreign journals magazines and 4 patents. Since 2008 he has been the Dean of Mechanical Engineering and Computer Science faculty of University in Bielsko-Biała.

Jacek Skrzypek, MEng, worked as an Assistant in the Department of Mechanical Engineering Fundamentals at University of Bielsko-Biała. He is engaged not only in the issues of calculating constructions of composite materials, but also in computer aided methods of design and engineering calculations. Actually works as a Designer in Avio Polska.

\section{KEY WORDS}

Laminate composite, FEM model, delamination.

\section{ABSTRACT}

The following article shows the FEM model of a laminate composite reinforced with fabric made of roving of carbon fibres. The model considers the internal structure of the reinforcement. This model was used for a simulation of a crack propagation in the 16-layers of carbon fibre laminate. The analyses were conducted in reference to the first way of cracking. The results of the simulation were then compared with the results of the experiments.

\section{Introduction}

Dynamic development of composite materials determines the need not only to improve methods for their manufacturing, but also calculation methods to predict the behaviour of these materials. Using computer simulations, the finite element method in particular, is the most commonly used method of computer-aided engineering calculations. In order to obtain adequate results, it is necessary to adopt an appropriate calculation model, which in the case of composite materials causes certain difficulties, especially for laminate composites in which the reinforcing fabric is made of roving of carbon fibres, glass or other materials. Calculations methods used nowadays are based on the Law of Mixtures which treats a composite (consisting of at least two components: reinforcement and warp) as a homogeneous material, i.e. having the 
characteristics which are the resultant of the components. This is not an appropriate assumption because strength properties depend not only on the properties of the reinforcement and warp, but also on the structure of the reinforcement and strength of the reinforcement-warp joint. In addition, an important aspect of strength calculations is the possibility to predict damage (cracks) and its growth which in composite materials depends on such factors as the type of reinforcement, its direction, type of warp as well as manufacturing technology (e.g. the possibility of defects in the structure). This paper describes a calculation model of a laminate composite reinforced with fabric made of roving of carbon fibres, and a simulation performed with the use of the model of the most common forms of damage growth which is composite delamination. The results are compared with the results of the experiment.

\section{Crack Resistance of Composite Materials}

In order to determine crack resistance, laws resulting from fracture mechanics of continuous media are applied where there are three basic ways of cracking, depending on the applied load (Fig. 1).

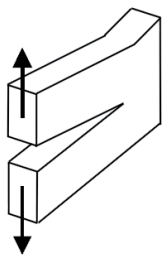

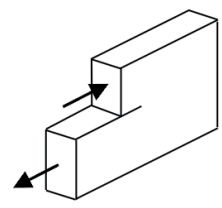

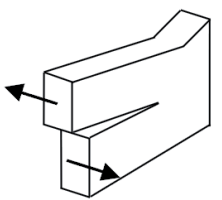

Fig. 1: Methods of loading items with a gap: a) method I - opening the crack, b) method II - longitudinal tear, c) method III - lateral I crosswise tear

To determine crack resistance, it is necessary to determine experimentally material constants (stress intensity factor $\mathrm{K}$ and the critical energy release rate $\mathrm{Gc}$ ) and the critical crack length I. These parameters allow quantitative behavioural assessment of material with a specific defect and determining the conditions under which the defect growth occurs and, as a result, the failure of a test piece. There are several methods for determining crack resistance of laminate composites mainly associated with the development of interlayer cracks i.e. delamination which, as already mentioned, is the most common form of damage and leads to reduction in stiffness, construction strength, and eventual destruction. Among the methods, there is one which uses cohesive elements (Cohesive Zone Model - CZM) [2] and which assumes that near the front of the gap, there is a material zone of length Ic that is gradually degraded after exceeding maximum stresses omax. Total separation occurs after exceeding maximum strains Emax, corresponding to $\sigma=0$ rather than omax. Cohesive elements, currently used in FEM commercial systems, have various characteristics. Figure 2 shows a diagram of the cohesive element operation, while Figure 3 presents its basic characteristics.

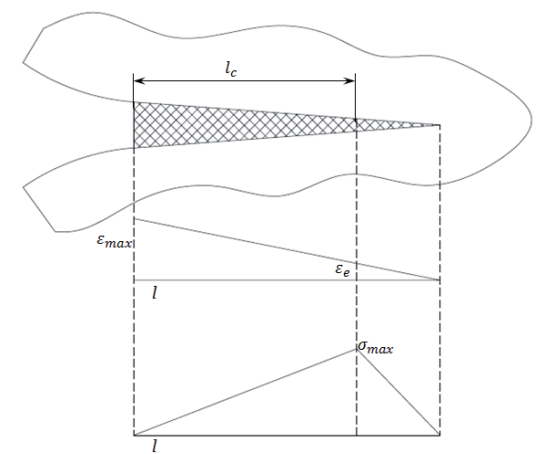

Fig. 2: Schematic diagram of cohesive element operation.
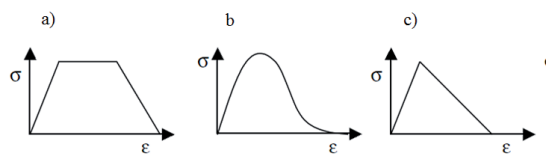

d)

Fig. 3: The characteristics of cohesive elements: a) trapezoidal, b) polynomial, c) bi-linear, d) exponential (strains in destruction zone, stresses in destruction zone).

The area under the graph represents the critical energy release rate $\mathrm{Gc}$, which can be easily determined by examining specific samples. Proper mapping of the zone length $\mathrm{Ic}$ and the number of elements assigned to this zone, strains $\varepsilon$ and $\varepsilon_{\text {max }}$ and stresses $\sigma_{\text {max }^{\prime}}$ requires a series of numerical tests that ultimately boil down to seeking characteristics parameters allowing to obtain the convergence of numerical solution with the result of the experiment. Due to the difficulty in measuring these values there is a high risk that the assumed values will incorrectly reflect the reality. The discrete model of a laminate has resultant material constants which is why the influence of the used reinforcement (weave) on delamination process is not taken into 
account, and hence it is a drawback of this method. Therefore, the following paper proposes a method of numerical simulation of delamination taking into consideration the reinforcement structure.

\section{Experimental Determination of Crack Resistance}

The first method of loading was applied in the studies. A DCB sample (Double Cantilever Beam), whose dimensions and the load method are shown in Figure 4, was used [3].

Samples were made of laminate consisting of 16
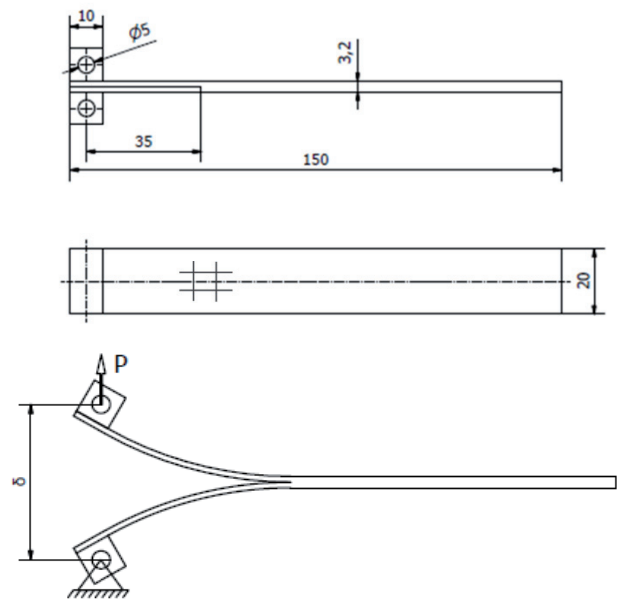

Fig. 4: DCB sample dimensions and scheme of the load.

layers of roving made of carbon fibre with a plain weave and the grammage of $196 \mathrm{~g} / \mathrm{m}^{2}$. The epoxy resin was used as a warp. The gap initiating the crack was made in the middle plane of the sample in lamination process. Metal holders were glued to the surface of the sample to allow attaching the sample in the measuring instrument. For the purpose of the analysis, it was assumed that the process of delamination can be mapped by means of the relation $\mathrm{P}(\delta)$. Therefore opening $\delta$ was applied and force $P$ was measured. The experiment was carried out for five samples with orientation of roving as in Figure 4. Figure 5 presents the results of the obtained measurements.

For the performed test of the sample, the material constant defining the composite resistance to cracking is the critical energy release rate which can be determined in a relatively simple manner by equation (1) [3]:

where: $\mathrm{G}_{\mathrm{lc}}$ - energy release rate for the first loading
$G_{I c}=\frac{3 P \delta}{2 B a}$

method P- loading, $\delta$ - opening, B - width of the sample, a - the length of the crack.

Table 1 shows the obtained values of energy re-
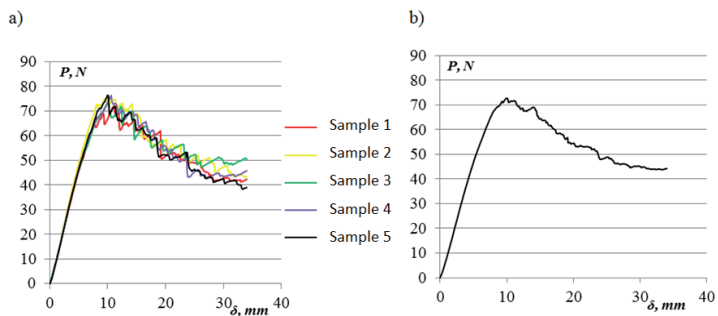

Fig. 5: Characteristic of dependence of breaking force $P$ on the opening $\delta$ : a) for individual test pieces, $b$ ) averaged (mean standard deviation $\sigma=2,41$ ).

lease rate $G_{k}$

The obtained measurements results were used in

Table 1: The value of the energy release rate

\begin{tabular}{|c|c|c|c|}
\hline Sample no. & $G_{l k}[N / m]$ & $\begin{array}{l}\text { Mean value } \\
G_{k}[N / m]\end{array}$ & $\begin{array}{l}\text { Standard } \\
\text { deviations } \\
\text { [N/m] }\end{array}$ \\
\hline 1 & 170 & \multirow{5}{*}{166} & \multirow{5}{*}{3,49} \\
\hline 2 & 164 & & \\
\hline 3 & 162 & & \\
\hline 4 & 169 & & \\
\hline 5 & 164 & & \\
\hline
\end{tabular}

order to carry out further numerical tests for the proposed discrete model.

\section{Discrete Calculation Model}

As mentioned in the introduction, numerical models used nowadays do not take into account the structure of the composite reinforcement. Only resultant material constants are considered. To eliminate this simplification, a discrete model was developed where composite components i.e. reinforcement and warp were separated. In the first stage, a parametric geometric model of the fabric was prepared. For this purpose, equations (2) describing the distribution of fibres in the used fabric with plain weave [1] were applied. Figure 6 presents a model of the so called unit cell (RUC-Repetitive Unit Cell) and geometric parameters used in the equations. 
Equations (2) describe central curves represent-

$$
\begin{aligned}
& z_{f}(x)=-\frac{h_{f}}{2} \cos \frac{\pi x}{a_{w}} \\
& z_{w}(y)=\frac{h_{w}}{2} \cos \frac{\pi y}{a_{f}}
\end{aligned}
$$

ing individual parts of roving. However, equations (3) describe the cross - sectional parameters of individual parts of roving.

Using the above-mentioned equations, it is pos-

$$
\begin{aligned}
& e_{f}(y)=\left|h_{f} \cos \frac{\pi y}{a_{f}}\right| \\
& e_{w}(x)=\left|h_{w} \cos \frac{\pi x}{a_{w}}\right|
\end{aligned}
$$
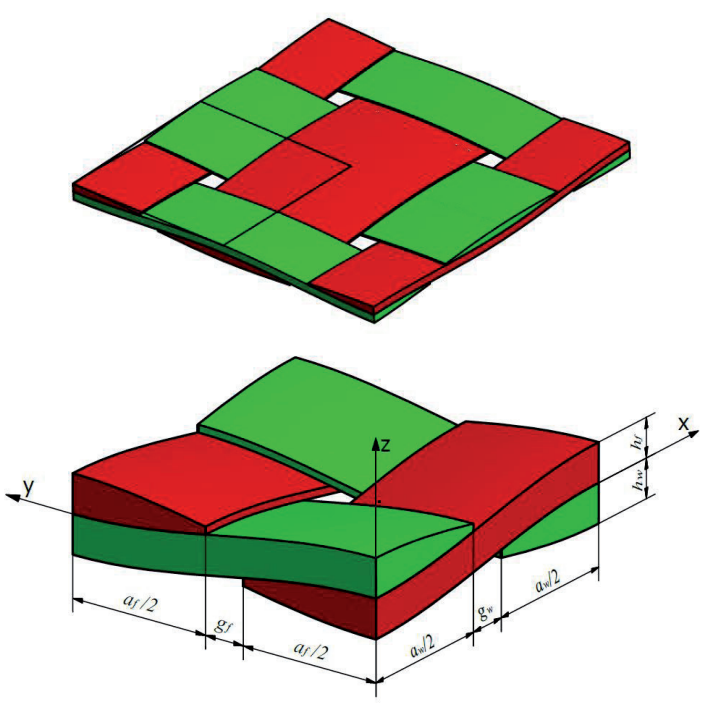

Fig. 6: CAD model of the fabric: a) (RUC) repetitive unit cell, b) fabric dimensions.

sible to derive surface equation, which limits the reinforcement fabric from top $z_{f}^{\text {top }}(x, y), z_{w}^{\text {top }}(x, y)$ and bottom $z_{f}^{b o t}(x, y), z_{w}^{b o t}(x, y)$.

In the next stage, a geometric model of the warp,

$$
\begin{aligned}
& z_{f}^{t o p}(x, y)=z_{f}(x)+\frac{1}{2} e_{f}(y) \\
& z_{f}^{b o t}(x, y)=z_{f}(x)-\frac{1}{2} e_{f}(y) \\
& z_{w}^{t o p}(x, y)=z_{w}(y)+\frac{1}{2} e_{w}(x) \\
& z_{w}^{b o t}(x, y)=z_{w}(y)-\frac{1}{2} e_{w}(x)
\end{aligned}
$$

which in the analyzed composite was epoxy resin, was developed. For this purpose, operations on solid bodies using Boolean algebra were applied. The parts which were filled with reinforcement fabric were removed from the cuboids with dimensions arising from the RUC dimensions using the equations of boundary surfaces (4). The result was a parametric geometric resin model shown in Figure 7.

The developed geometry model can be used

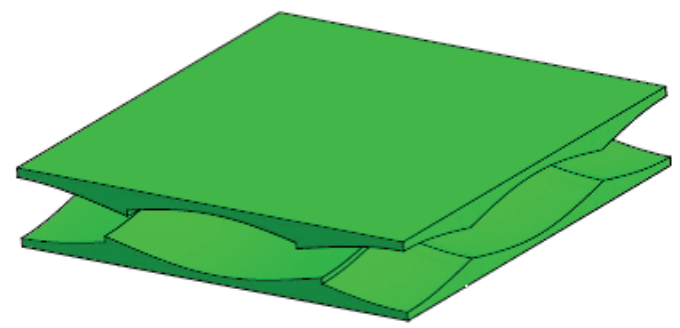

Fig. 7: Geometric resin model

for generating models of composites with different types and grammage of reinforcement fabric, provided that the weave is plain. For the purpose of the analysis, a discrete calculation model was developed using the finite element method. Discretization was performed in the MSC Patran, and the calculations were done in the MD Nastran. Linear three-dimensional elements (CHEX) defined by the 8 nodes were used for discretization, each node having three degrees of freedom [4]. It was assumed that the part of the model representing the resin would be made of isotropic material, whereas fabric of carbon would be made of orthotropic material instead, which requires 9 materia constants.

Due to the lack of material data of the roving of carbon fibres treated as an orthotropic material, it was necessary to carry out calibration process of the FEM model, i.e. determination of material constants $\left(\mathrm{E}_{\mathrm{xx}}, \mathrm{E}_{\mathrm{yy}}, \mathrm{E}_{\mathrm{zz}}, \mathrm{G}_{\mathrm{xy}}, \mathrm{G}_{\mathrm{yz}}, \mathrm{G}_{\mathrm{zx}}, v_{\mathrm{xy}}, v_{\mathrm{yz}}, v_{\mathrm{zx}}\right)$. For this purpose, an additional test was performed consisting in the static tensile test of a flat composite sample consisting of a single fabric layer. The sample was prepared so that its thickness corresponded to the thickness of a single layer in the DCB sample. The result of the study was characteristics $\sigma(\varepsilon)$. Next, a discrete model of the flat sample was prepared and the calibration process took place. This process was based on solving an optimization 
task [5] where the vector of decision variables and the objective function are, $\bar{x}=\left[x_{1}, x_{2}, \ldots, x_{9}\right]^{T}=$ $=\left[E_{x x}, E_{y y}, E_{z z}, G_{x y}, G_{y z}, G_{z x}, \nu_{x y}, \nu_{y z}, \nu_{z x}\right]^{T} \quad$ and $Q(\bar{x})=\sum_{i=1}^{2}[\Delta \varepsilon(P)]^{p} \rightarrow \mathrm{m}$ where $\Delta \varepsilon(P)=\varepsilon_{\text {MES }}(P)-\varepsilon_{E X P}(P)$ and $\varepsilon_{M E S}$ strain of measuring length in the FEM model, $\varepsilon_{E X P}$ strain of measuring length determined experimentally, $P$ - sample loading force.

Direction $x$ is consistent with the axis of the roving. The task was solved using SOL 200 optimization module for MD Nastran. As a result of solving the optimization problem, engineering constants were obtained: $\mathrm{E}_{\mathrm{xx}}=227 \mathrm{GPa}, \mathrm{E}_{\mathrm{yy}}=5,6 \mathrm{GPa}, \mathrm{E}_{z z}=5,6 \mathrm{GPa}$, $\mathrm{G}_{\mathrm{xy}}=4,2 \mathrm{GPa}, \mathrm{G}_{\mathrm{yz}}=2,6 \mathrm{GPa}, \mathrm{G}_{z \mathrm{x}}=4,2 \mathrm{GPa}, v_{\mathrm{xy}}=0,27$, $v_{y z}=0,32, v_{z x}=0,03$. These data were then used to define the discrete model of the DCB sample. Due to the size of the task (the number of finite elements) it was decided that the simulation process would take into account only the zone of destruction (Fig. 8). Moreover, the model was symmetric with respect to the middle plane of the sample, therefore symmetry constraints were introduced in order to accelerate the calculations. The Fig. 8b presents the discrete calculation model of the unit cell (RUC) used to model the zone of destruction. The remainder of the sample was modelled by using scarce division into finite elements.

To simulate delamination, damage criterion
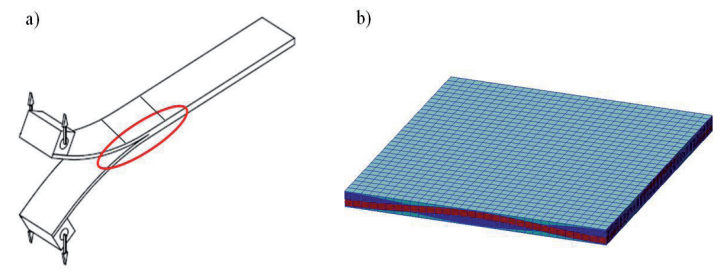

Fig. 8: Sample DCB model: a) the zone of destruction, b) unit cell in the destruction zone.

was adopted. Exceeding permissible strains in the nodes corresponding to the epoxy resin - the warp of the sample was accepted as the criterion for damage. To confirm the validity of the assumption, preliminary calculations were carried out where the discrete model was loaded by assuming the maximum force $P=72.6 \mathrm{~N}$ obtained during tests (Fig. 5b). Fig. 9 shows values of the resin strain in the destruction zone obtained during the simulation.

Calculations proved that the maximum strain
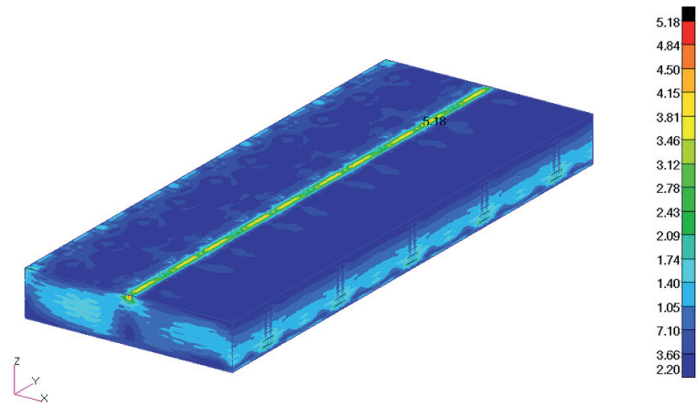

Fig. 9: Maximum strain of the resin in the destruction zone in [\%].

is $5.18 \%$, which confirmed the validity of the assumption according to the manufacturer - resin damage occurs when strains exceed the value of $5 \div 6 \%$. The next stage was to simulate delamination based on the algorithm shown in Figure 10.

In the following iterations of the algorithm, the

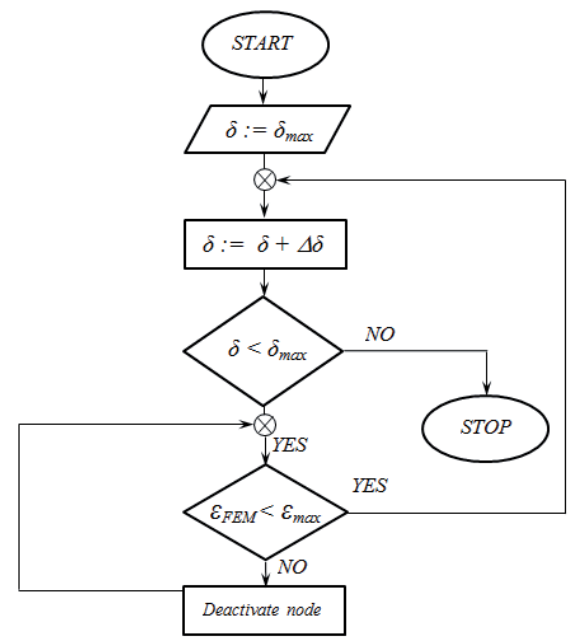

Fig. 10: Block diagram of delamination simulation.

opening $\delta$ was increased (Fig.4) by $\Delta \delta$ to obtain the value $\delta_{\text {max' }}$ which corresponded to the state of the sample failure and was determined experimentally (Fig. 5b). At the same time, when the relative strain in the node of the FEM model of the element modelling resin $\left(\varepsilon_{\text {MES }}\right)$ exceeded the critical value $\left(\varepsilon_{\max }=6 \%\right)$, at which cracking of the resin occurs, the element was removed from the FEM model in the next iteration. Location of items removed from the model in subsequent iterations allowed us to simulate the path of propagating the crack in the composite, initiated by a gap in the DCB sample, increasing under the influence of the growing 
gap opening (Fig. 5). Figure 11 shows delamination process propagation in the destruction zone in subsequent iterations $i$. The microscopic tests of the sample crack surface revealed that the crack was not caused by resin detachment from the fibres of the fabric (exceeding adhesive forces), but decohesion of the resin itself (internal discontinuity). Numerical simulations confirmed this phenomenon. Maximum strains appear on the crack surface of the sample (in the plane of symmetry) and are not transmitted to the nodes joining the fabric with the resin. The simulation of crack propagation was carried out until the opening reached the value of $\delta_{\max }=20 \mathrm{~mm}$, and the results were compared with the results of the experiment, which is shown in the form of a diagram in Figure 12.

As shown in the chart above, a good conver-

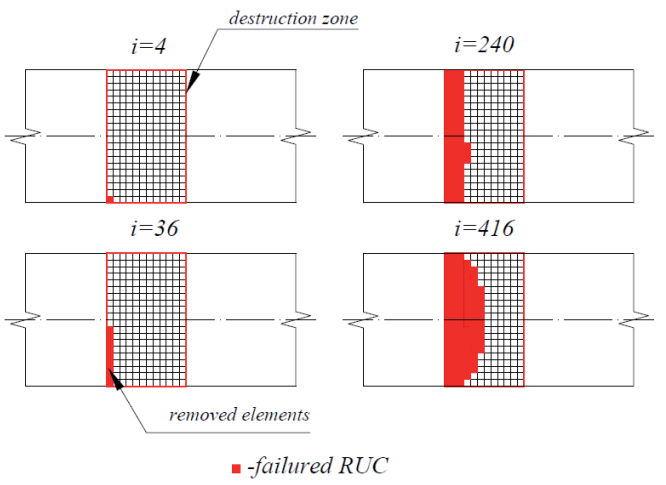

Fig. 11: Delamination process propagation in subsequent iterations $i$.

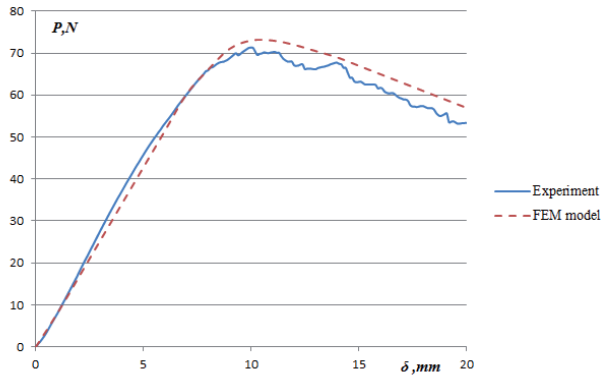

Fig. 12: Comparison of real sample and discrete model characteristics.

gence was obtained of numerical simulation with the results of the experiment (the Pearson cross correlation coefficient is 0.996). Deviations of characteristics may be caused by defects in materials occurring during sample preparation (e.g. air bubbles Fig. 13). It should be emphasized that it is important to adopt an appropriate damage criterion, i.e. the numerical value of critical strains emax, which depends on many factors such as the proportion of resin and hardening agent, reinforcement saturation with warp, soaking heat and soaking time during lamination, i.e. from the technology used by a particular manufacturer. In order to use the proposed methodology to assess the strength of real structures made of composites, it is necessary to solve the problem of numerical efficiency of the FEM model. The analyzed DCB sample consisted of 332800 elements and had 353 754 nodes. The time of a single algorithm iteration according to the scheme in Figure 10 (a computer with an Intel Core i5-3450, 4GB RAM) was approximately 40 minutes.

The authors' experience in the analysis of similar

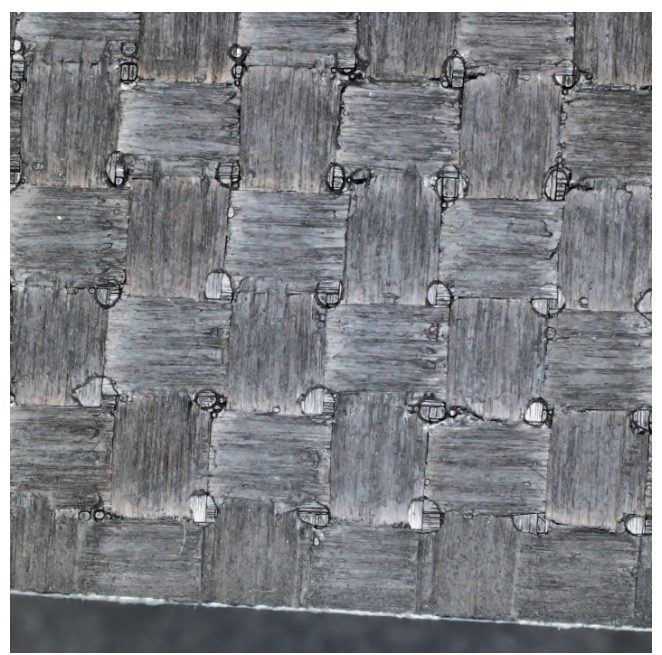

Fig. 13: DCB sample crack surface with visible defects which occurred in manufacturing process.

issues suggests that the efficiency of numerical FEM models can be significantly improved by reducing the size of the task through the use of the so-called superelements available in programmes of FEM analysis. Application of the concept of a superelement can give measurable benefits, since the composite is composed of repeating elements - RUC. Thus, it is sufficient to define superelement for one RUC and use it in the construction of the whole model. Paper [6] has shown that the use of the concept of superelement in the analysis of deflection of a flat sample with similar dimensions made of the same composite as the test sample, 
reduced model dimensions from initial 139887 to 2928 degrees of freedom and therefore the calculation time was reduced from $143 \mathrm{~s}$ to $2.9 \mathrm{~s}$ which is nearly 50 times. Similar effects can be expected for simulating delamination.

\section{Summary and Conclusions}

The research on the development of the FEM model for simulating delamination growth in fabric-reinforced laminate composites allow the following conclusions:

methods of delamination simulation, used currently in commercial systems FEM, are not sufficiently useful, since they require from the user the knowledge of all parameters, which are difficult, if not impossible to determine by experimental studies,

- it is desirable to take into account the composite internal structure (number of layers, their orientation and weave of reinforcement fabric) in numerical simulations because they largely influence the obtained results and their interpretation,

the methodology, which is proposed in the paper, of building the FEM model of laminate composites reinforced with fabric made of carbon fibres, allowed to obtain a model that can simulate the process of composite delamination compatible with the experiment,

- material constants of the composite FEM model should take into account the technology of production and capabilities of a particular manufacturer of composite constructions (FEM model calibration with the use of the experiment results).

The authors predict the development of the described composite FEM model in order to build a useful, engineering tool for the analysis of real composite structures.

\section{References}

[1] Barbero Ever J.: Introduction to composite material design, Taylor \& Francis 2010.

[2] Czarnocki P., Dobrzański P.: Wykorzystanie elementów kohezyjnych do symulacji rozwoju rozwarstwień w laminatach polimerowych, Przegląd Mechaniczny 6/2012

[3] JOchelski S.: Metody doświadczalne mechaniki kompozytów konstrukcyjnych, WNT, Warszawa 2004.

[4] Rakowski G., Kacprzyk Z.: Metoda elementów skończonych w mechanice konstrukcji, Oficyna Wydawnicza Politechniki Warszawskiej, Warszawa 2005
[5] BStadnicki J., Tokarz Z:: Model obliczeniowy kompozytu warstwowego - kalibracja z wykorzystaniem optymalizacji, XI Szkoła Komputerowego Wspomagania Projektowania, Wytwarzania i Eksploatacji: materiały konferencyjne, Jurata 2006.

[6] Stadnicki J., Tokarz Z.: Structutal analysis of selected constructions made of fabric laminate composite, Acta Mechanica Slovaca, Koszyce 2007, R.11 [nr] 4-A 